\title{
Lemons Markets and the Transmission of Aggregate Shocks
}

\author{
Pablo Kurlat * \\ Stanford University
}

July 21, 2011

\begin{abstract}
I study a dynamic economy featuring adverse selection in asset markets. Borrowingconstrained entrepreneurs sell past projects to finance new investment, but asymmetric information creates a lemons problem. I show that this friction is equivalent to a tax on financial transactions. The implicit tax rate responds to aggregate shocks, amplifying the response of the real economy and generating cyclical variation in various measures of liquidity.
\end{abstract}

Financial markets are fragile, volatile and occasionally shut down entirely. The extent to which this instability is related to real economic variables is an important open question for macroeconomics. In this paper I develop a model of financial imperfections to explain how instability can result from macroeconomic shocks and in turn amplify and propagate them.

I focus on one specific financial market imperfection: asymmetric information about the quality of assets. There are several reasons for this focus. First, both in theory (Hart and Moore 1994, Kiyotaki and Moore 1997) and in practice, assets of various kinds are extensively used to enable intertemporal transactions. If there is asymmetric information about asset qualities, which is a natural assumption, this has the potential to interfere with a large subset of financial transactions. Second, asymmetric information is a central concern in corporate finance. Following Myers and Majluf (1984), asymmetry of information between firm managers and their outside investors is seen as a key determinant of firms' capital structure. Third,

*I am deeply indebted to George-Marios Angeletos, Ricardo Caballero, Bengt Holmström and especially Iván Werning for their invaluable guidance. I also thank Daron Acemoglu, Sergi Basco, Francisco Buera, Martín Gonzalez-Eiras, Guido Lorenzoni, Monika Piazzesi, Krishna Rao, Julio Rotemberg, Martin Schneider, Jean Tirole, Robert Townsend and participants at the MIT Macroeconomics Lunch, Theory Lunch and International Breakfast, as well a various seminar participants. Correspondence: Department of Economics, Stanford University. 579 Serra Mall, Stanford, CA, 94305. Email: pkurlat@stanford.edu 
sometimes financial markets simply cease to function, as documented by Gorton and Metrick (2009) for the repo market in 2007-2009. Since Akerlof (1970), it is well known that the complete breakdown of trade is a theoretical possibility in economies with asymmetric information. This means that asymmetric information at least has the potential to explain extreme crises and may shed light on less extreme phenomena as well.

I embed imperfect financial markets in a simple dynamic macroeconomic model. In the model, entrepreneurs hold the economy's stock of capital. Every period, they receive idiosyncratic investment opportunities, i.e. opportunities to convert consumption goods into capital. The only way to obtain financing is to sell existing assets. These are bought by entrepreneurs who in the current period have poor investment opportunities. Unfortunately, some fraction of existing assets are useless lemons and buyers can't tell them apart from high quality assets (nonlemons).

I show that the lemons problem introduces a wedge between the return on saving and the cost of funding, persuading some entrepreneurs to stay out of the market. This is formally equivalent to introducing a tax on financial transactions. The tax lowers asset prices, the rate of return obtained by uninformed investors and the rate of capital accumulation. Furthermore, the implicit tax rate depends on the proportions of lemons and nonlemons sold, which respond to aggregate shocks.

I consider three types of aggregate shocks: a standard productivity shock, an investment shock which affects all entrepreneurs' investment opportunities proportionally and an informational shock. I show that for all of these, negative shocks will lead to a worsening of financial market imperfections (as measured by the implicit tax rate), and vice versa. For informational shocks, the effect is quite direct: an exogenous worsening of information increases frictions. For investment shocks, the effect is due to the fact that investment opportunities are the source of gains from trade; fewer investment opportunities reduce the gains from trade and lead to greater frictions. For productivity shocks, the mechnism is driven entirely by general equilibrium effects. Negative productivity shocks lower output, which reduces the supply of savings; the rate of return on saving rises, asset prices fall and sellers of nonlemons drop out of the market, which worsens the adverse selection problem. Overall, the endogenous response of financial frictions amplifies the effects of shocks on the real economy.

Due to general equilibrium forces, financial frictions in the model are sensitive to wealth effects. This is also the case in Kiyotaki and Moore (1997), Bernanke and Gertler (1989), and Carlstrom and Fuerst (1997) among others, who analyze how the wealth of productive-butconstrained agents affects frictions. In this model, however, wealth effects operate through a different channel since the decision of entrepreneurs with good investment opportunities tokeep or sell their nonlemons is independent of wealth. Instead, the model highlights the importance of the balance sheets of less-productive agents, because they govern the demand for assets. 
In addition to providing an amplification mechanism, the model can account for a number of stylized facts about business cycles. The model predicts that frictions will increase in recessions, which may explain the procyclical liquidity of real assets documented by Eisfeldt and Rampini (2006). While different types of cyclical frictions could account for this, other predictions are specific to asymmetric information. The model predicts that the decision to sell an asset is a more negative signal about the asset's quality in recessions than in expansions, which is consistent with the evidence in Choe et al. (1993) on seasoned equity issues. Furthermore, unlike other theories of financial frictions that predict that outside financing is either a fixed fraction of firms' funding or is even countercyclical, this model predicts that outside financing is procyclical, consistent with the evidence in Covas and Den Haan (2011). The model further predicts that large negative shocks lead financial markets to shut down entirely. This type of sharp decrease in the volume of financial transactions has been documented for instance by Ivashina and Scharfstein (2010).

In the model, entrepreneurs' investment opportunities are heterogeneous, which implies that the distribution of investment across entrepreneurs matters. Increased frictions in recessions distort the allocation of investment and worsen the average rate of transformation of consumption goods into capital goods. Justiniano, Primiceri and Tambalotti (2008) have found this type of effect to play a large role in aggregate fluctuations and have further found that it correlates with measures of disturbances in financial markets.

The structure of the model is close to that developed by Kiyotaki and Moore (2005, 2008), which also features random arrival of investment opportunities, borrowing constraints and partially illiquid assets. They use a reduced-form model of the limitations on selling capital and investigate whether this may explain why easier-to-sell assets command a premium. In contrast, I develop an explicit model of what the sources of these limitations are, which allows me to investigate how they respond to aggregate shocks.

Following Stiglitz and Weiss (1981), adverse selection played an important early role in the theory of credit markets. Recent contributions include Bolton et al. (2009) and Malherbe (2009). In macroeconomic settings, the issue has been studied by Mankiw (1986), de Meza and Webb (1987) and House (2006). Hendel and Lizzeri (1999) and Hendel, Lizzeri and Siniscalchi (2005) study the dynamic nature of the lemons problem, focusing on durable goods market. With durable goods, the gains from trade arise from differences in tastes and random depreciation, whereas in this model trade in assets is merely a instrument for intertemporal trades.

Closest to this paper is Eisfeldt (2004). In her model, entrepreneurs hold different vintages of projects and cannot diversify risks. Financial transactions are desirable because they enable entrepreneurs to smooth consumption when they suffer poor realizations of income from previous vintages of risky projects. Thus her paper is about how asymmetric information interferes with risk-sharing whereas mine is about how it interferes with the financing of investment. 
On a more technical side, one limitation of her approach is that it requires keeping track of the distribution of portfolio holdings across different vintages of projects, for all entrepreneurs, which makes it necessary to limit attention to numerical simulations of steady states or simple deterministic cycles, since stochastic simulations are computationally infeasible. Recently, Bigio (2011) has extended a variant of my model, introducing labour market frictions, and shown that it can quantitatively match some of the features of the 2007-2009 recession.

\section{The environment}

Households. There are two kinds of agents in the economy, workers and entrepreneurs. There is a continuum of mass $L$ of identical workers, each of whom supplies one unit of labour inelastically; they have no access to financial markets, so they just consume their wage. In addition, there is a continuum of mass one of entrepreneurs, indexed by $j$, who have preferences

$$
\mathbb{E} \sum_{t=0}^{\infty} \beta^{t} u\left(c_{t}^{j}\right)
$$

with $u\left(c_{t}^{j}\right)=\log \left(c_{t}^{j}\right)$. They do not work. ${ }^{1}$

Technology. Consumption goods are produced combining capital and labour. The capital stock consists of projects owned by entrepreneurs. Entrepreneur $j$ 's holdings of projects are denoted $k_{t}^{j}$ so the aggregate capital stock is $K_{t}=\int k_{t}^{j} d j$. Every period a fraction $\lambda$ of projects becomes useless or "lemons". Each entrepreneur's holdings of projects is sufficiently well diversified that the proportion $\lambda$ applies at the level of the individual entrepreneur as well. Each of the $(1-\lambda) K_{t}$ projects that do not become lemons is used for production, so that output is $Y_{t}=Y\left((1-\lambda) K_{t}, L ; Z_{t}\right) . Y$ is a constant-returns-to-scale production function that satisfies Inada conditions and $Z_{t}$ is exogenous productivity; the properties of the model are such that the stochastic process that governs $Z_{t}$ may be left unspecified. The marginal product of capital and labour are denoted $Y_{K}$ and $Y_{L}$ respectively.

The aggregate resource constraint is

$$
L c_{t}^{w}+\int\left(c_{t}^{j}+i_{t}^{j}\right) d j \leq Y\left((1-\lambda) K_{t}, L ; Z_{t}\right)
$$

where $c_{t}^{w}$ denotes consumption per worker, $c_{t}^{j}$ is consumption by entrepreneur $j$ and $i_{t}^{j}$ represents physical investment by entrepreneur $j$.

Physical investment is undertaken in order to convert consumption goods into projects

\footnotetext{
${ }^{1}$ Giving entrepreneurs no labour income makes their decisions linear in their capital holdings, which simplifies the characterization of their policy functions.
} 
for period $t+1$. Each entrepreneur can transform consumption goods into projects using an idiosyncratic linear technology with a stochastic marginal rate of transformation $A_{t}^{j}$. $A_{t}^{j}$ is iid across time and entrepreneurs and is drawn from a continuous distribution $F$ with finite mean and continuous density $f$. In addition, each nonlemon project turns into $\gamma$ projects at $t+1$, so it is possible to interpret $1-\gamma(1-\lambda)$ as an average rate of depreciation. Aggregate capital accumulation is given by

$$
K_{t+1}=\gamma(1-\lambda) K_{t}+\int i_{t}^{j} A_{t}^{j} d j
$$

Allocations. The exogenous state of the economy is $z_{t} \equiv\left\{Z_{t}, \bar{A}_{t}\right\}$. It includes productivity $Z_{t}$ and the function $\bar{A}_{t}$, which maps each entrepreneur to a realization of $A_{t}^{j}$. An allocation specifies consumption and investment for each agent in the economy and aggregate capital after every history: $\left\{c^{w}\left(z^{t}\right), c^{j}\left(z^{t}\right), i^{j}\left(z^{t}\right), K\left(z^{t}\right)\right\}$.

Information. At time $t$ each entrepreneur knows which of his own projects have become lemons in the current period, but the rest of the agents in the economy do not. Informational asymmetry lasts only one period. At $t+1$, everyone is able to identify the projects that became lemons at $t$, so they effectively disappear from the economy, as illustrated in figure 1 . This assumption is made for simplicity as it eliminates the need to keep track of projects of different vintages. Daley and Green (2009) study the strategic issues that arise when informational asymmetries dissipate gradually over time.

The investment opportunity $A_{t}^{j}$ is and remains private information to entrepreneur $j$.

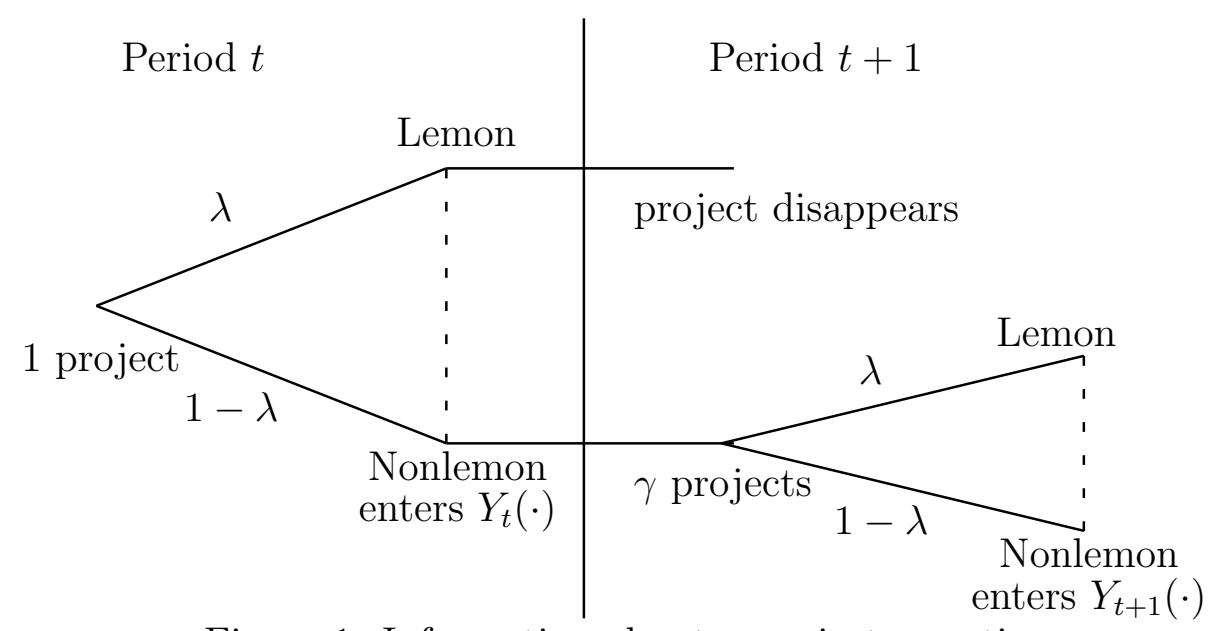

Figure 1: Information about a project over time 


\section{Benchmark allocations}

\subsection{Complete markets}

Suppose all the information was public and there were complete competitive markets. Let $X \equiv\{z, \bar{K}\}$ be the aggregate state variable, where $\bar{K}$ maps entrepreneurs to capital holdings. Since lemons are useless their price will be zero. In factor markets, entrepreneurs hire workers at a wage of $w(X)=Y_{L}(X)$ and obtain dividends of $r(X)=Y_{K}(X)$ for each nonlemon project. ${ }^{2}$ Consumption goods are traded for nonlemon projects, ex-dividend, at a spot price of $p_{N L}(X)$ goods per nonlemon project. State-contingent claims are traded one period ahead: the stateprice density is $\rho\left(X, X^{\prime}\right)$.

Entrepreneurs solve:

$$
\begin{gathered}
\quad V(k, b, X)=\max _{c, k^{\prime}, i, d_{N L}, b\left(X^{\prime}\right)}\left[u(c)+\beta \mathbb{E}\left[V\left(k^{\prime}, b\left(X^{\prime}\right), X^{\prime}\right) \mid X\right]\right] \\
\text { s.t. } \quad c+i+p_{N L}(X) d_{N L}+\mathbb{E}\left[\rho\left(X, X^{\prime}\right) b\left(X^{\prime}\right)\right] \leq r(X)(1-\lambda) k+b \\
k^{\prime}=\gamma\left[(1-\lambda) k+d_{N L}\right]+A^{j}(X) i \\
i \geq 0, d_{N L} \geq-(1-\lambda) k
\end{gathered}
$$

Constraint (4) is the entrepreneur's budget constraint. The entrepreneur's available goods are equal to the dividends from his nonlemons $r(1-\lambda) k$ plus net state-contingent goods bought the previous period $b$. These are used for consumption plus physical investment plus net purchases of nonlemons $d_{N L}$ plus purchases of state-contingent goods for the next period. Constraint (5) keeps track of the entrepreneur's holdings of projects. $k^{\prime}$, the total number of projects next period, is equal to the nonlemon projects he owns at the end of the current period, which are $(1-\lambda) k+d_{N L}$ and have grown at rate $\gamma$, plus the projects that result from his physical investment in this period, $A^{j}(X) i$. Constraint (6) states that investment must be nonnegative and sales of nonlemons are limited by the number of nonlemons the entrepreneur owns.

The first order conditions with respect to $i$ and $d_{N L}$ imply: ${ }^{3}$

$$
A^{j}(X) \leq \frac{\gamma}{p_{N L}(X)}, \text { with equality if } i>0
$$

Let $A^{\max }$ be the highest possible value of $A$. At each history there will be an entrepreneur

\footnotetext{
${ }^{2} \mathrm{As}$ is standard, this could be the result of competitive firms renting capital from entrepreneurs or of entrepreneurs operating the productive technology themselves. With asymmetric information, the latter interpretation avoids the need to analyze adverse selection in the rental market.

${ }^{3}$ This uses the fact that constraint $d_{N L} \geq-(1-\lambda) k$ will not bind in equilibrium because a project can be replicated with contingent securities.
} 
(the best entrepreneur) with $A^{j}(X)=A^{\max }$ who can transform each consumption good into $A^{\max }$ projects at $t+1$. Equation $(7)$ then implies that $p_{N L}(X)=\frac{\gamma}{A^{\max }}$ for all $X$. The best entrepreneur is the only one to undertake physical investment. He finances this investment by selling claims to consumption goods one period ahead (i.e. borrowing) which he then satisfies with the dividends plus proceeds of selling the newly created projects in the spot market. Since $r(X)$ is stochastic, capital is a risky asset, and the best entrepreneur will use state-contingent securities to share this risk with the rest of the entrepreneurs. Complete markets imply that risk-sharing will be perfect.

Complete markets are actually not indispensable for achieving this allocation. Suppose there is a market for selling new projects at the same instant that they are built, when they still haven't split into lemons and nonlemons. In equilibrium these new projects will trade at a price $p_{N E W}(X)=\frac{1}{A^{m a x}}$, the marginal cost for the best entrepreneur, who will be the only one to build them. Entrepreneurs would have no further need to trade contingent securities because (i) their idiosyncratic realizations of $A^{j}$ would have no effect on their budget sets, so they would bear no idiosyncratic risk and (ii) they have identical homothetic preferences and their exposure to aggregate risk is proportional to their capital, which is their only asset. Hence, they would attain the same allocation as with complete markets.

Proposition 1. With complete markets, all investment is undertaken by the entrepreneur with $A^{j}=A^{\max }$; all entrepreneurs obtain $A^{\max }$ projects per consumption good saved and bear no idiosyncratic risk. The aggregate economy behaves just like an economy where the rate of transformation of consumption goods into projects is fixed at $A^{\max }$, there is a representative entrepreneur and workers are constrained to live hand-to-mouth. The same allocation is obtained if the only market that exists is for newly-created projects.

\subsection{Borrowing constraints but still no informational asymmetry}

For various reasons, it may be difficult for an entrepreneur to borrow against his future wealth, i.e. to choose negative values of $b\left(X^{\prime}\right)$. For instance, he may be able to run away with his wealth rather than honouring his debts. ${ }^{4}$ I what follows, I make the extreme assumption that borrowing is impossible, which in equilibrium implies lending is impossible as well. Thus, the entrepreneur will solve program (3), with the added constraint:

$$
b\left(X^{\prime}\right)=0
$$

As a result, the only market that exists is for ex-dividend sales of existing projects. This is intended to represent not just literal sales of used machines but more broadly the use of

\footnotetext{
${ }^{4}$ Alternatively, he could refuse to exert effort if he has pledged his output, as in Holmström and Tirole (1998).
} 
existing assets as collateral for borrowing. In particular, selling projects is the only way to achieve intertemporal trades. ${ }^{5}$ Importantly, only existing projects, not newly-built ones, may be traded, a distinction also emphasized by Kiyotaki and Moore (2008).

As a result of constraint (8), the best entrepreneur will not be able to undertake all the investment in the economy. Instead, there will be a cutoff $A^{*}(X)=\frac{\gamma}{p_{N L}(X)}$ such that entrepreneurs with $A^{j}(X)<A^{*}(X)$ will not invest and entrepreneurs with $A^{j}(X)>A^{*}(X)$ will sell all their existing nonlemons in order to obtain consumption goods for investment.

This equilibrium is inefficient in two related ways. First, the economy does not exclusively use the most efficient technology $\left(A^{\max }\right)$ for converting consumption goods into projects. Second, entrepreneurs are exposed to idiosyncratic risk. If they draw a low value of $A^{j}$, they must convert their consumption goods into projects through the market, which only provides a return $A^{*}(X)$, whereas if they draw a higher value they convert them at a rate $A^{j}(X)$.

\section{Asymmetric information}

Assume now that only the owner of a project knows whether it is a lemon, and each entrepreneur observes only his own $A^{j}$. Those who purchase projects have rational expectations about $\lambda^{M}$, the proportion of lemons among the projects that are actually sold in the market. Selling individual projects is still the only financial transaction allowed. ${ }^{6}$

With asymmetric information, entrepreneurs do not observe the state of the economy because they do not observe other entrepreneurs' investment opportunities. Fortunately, the endogenous aggregate variables $r, p$ and $\lambda^{M}$ that are relevant for the entrepreneur's decisions depend only on productivity and capital, which the entrepreneur does observe. Therefore I will look for a recursive competitive equilibrium with $X \equiv\{Z, \Gamma\}$ as a state variable, where $\Gamma(k, A)$ is the cumulative distribution of entrepreneurs over holdings of capital and investment opportunities. $^{7}$ The relevant state variable for entrepreneur $j$ 's problem is $\left\{k^{j}, A^{j}, X\right\}$ so (dropping

\footnotetext{
${ }^{5}$ The difference between selling a project and promising $b$ with the project as collateral is that if the value of the project at $t+1$ is $v$ the buyer/lender obtains $v$ in case of a sale and $\min \{v, b\}$ in case of collateralized borrowing. Given the binary outcomes for projects, if there was no aggregate risk, both transactions would be identical up to a normalization, paying a fixed positive amount if the project is still a nonlemon at $t+1$ and zero if it becomes a lemon. Due to aggregate risk, the payoff in case the project is still a nonlemon is not fixed, so the two transactions differ slightly. Still, they share the feature that the expected value of an entrepreneur's existing projects determines the extent to which he is able to obtain consumption goods for new investment.

${ }^{6}$ In particular, I do not allow for selling a representative portfolio of projects, which would have no adverse selection. This could result from the difficulty of determining what the entrepreneur's total holdings are or from a cost in bundling the portfolio, as assumed by Kiyotaki and Moore (2003). I also do not allow for other securities besides outright sales. DeMarzo and Duffie (1999) and Nachman and Noe (1994) analyze security design in related settings.

${ }^{7}$ Since $A^{j}$ is $i i d$, then it is independent of $k^{j}$ and $\Gamma$ is just the product of $F$ and the distribution of $k$. The more general formulation could easily accommodate the case where an entrepreneur's individual $A^{j}$ has some persistence, which would create correlation between $k^{j}$ and $A^{j}$.
} 
the $j$ superscript) he solves the following program:

$$
\begin{gathered}
V(k, A, X)=\max _{c, k^{\prime}, i, s_{L}, s_{N L}, d}\left[u(c)+\beta \mathbb{E}\left[V\left(k^{\prime}, A^{\prime}, X^{\prime}\right) \mid X\right]\right] \\
\text { s.t. } \quad c+i+p(X)\left[d-s_{L}-s_{N L}\right] \leq r(X)(1-\lambda) k \\
k^{\prime}=\gamma\left[(1-\lambda) k+\left(1-\lambda^{M}(X)\right) d-s_{N L}\right]+A i \\
i \geq 0, d \geq 0 \\
s_{L} \in[0, \lambda k], s_{N L} \in[0,(1-\lambda) k]
\end{gathered}
$$

Program (9) incorporates the borrowing constraint (8) and the fact that the price $p(X)$ applies equally for sales of lemons $s_{L}$, sales of nonlemons $s_{N L}$ and purchases of projects of unknown quality $d$, a proportion $\lambda^{M}(X)$ of which turn out to be lemons.

Denote the solution to this program by $\left\{c(k, A, X), k^{\prime}(k, A, X), i(k, A, X), s_{L}(k, A, X)\right.$, $\left.s_{N L}(k, A, X), d(k, A, X)\right\}$ and define the supply of lemons and nonlemons, total supply of projects and demand of projects respectively as $S_{L}(X) \equiv \int s_{L}(k, A, X) d \Gamma(k, A), S_{N L}(X) \equiv$ $\int s_{N L}(k, A, X) d \Gamma(k, A), S(X) \equiv S_{L}(X)+S_{N L}(X), D(X) \equiv \int d(k, A, X) d \Gamma(k, A)$.

Definition 1. An equilibrium consists of prices $\{p(X), r(X), w(X)\} ;$ market proportions of lemons $\lambda^{M}(X)$; a law of motion $\Gamma^{\prime}(X)$ and associated transition density $\Pi\left(X^{\prime} \mid X\right)$; a value function $V(k, A, X)$ and decision rules $\left\{c^{w}(X), c(k, A, X), k^{\prime}(k, A, X), i(k, A, X), s_{L}(k, A, X)\right.$, $\left.s_{N L}(k, A, X), d(k, A, X)\right\}$ such that $(i)$ factor prices equal marginal products: $w(X)=Y_{L}(X)$, $r(X)=Y_{K}(X)$; (ii) workers consume their wage $c^{w}(X)=w(X)$; (iii) $\left\{c(k, A, X), k^{\prime}(k, A, X)\right.$, $\left.i(k, A, X), s_{L}(k, A, X), s_{N L}(k, A, X), d(k, A, X)\right\}$ and $V(k, A, X)$ solve program (9) taking $p(X), r(X), \lambda^{M}(X)$ and $\Pi\left(X^{\prime} \mid X\right)$ as given; (iv) the market for projects clears: $S(X) \geq$ $D(X)$, with equality whenever $p(X)>0 ;(v)$ the market proportion of lemons is consistent with individual selling decisions: $\lambda^{M}(X)=\frac{S_{L}(X)}{S(X)}$ and (vi) the law of motion of $\Gamma$ is consistent with individual decisions: $\Gamma^{\prime}(k, A)(X)=\int_{k^{\prime}(\tilde{k}, \tilde{A}, X) \leq k} d \Gamma(\tilde{k}, \tilde{A}) F(A)$.

\subsection{Equilibrium conditions}

I solve the entrepreneur's problem and find equilibrium conditions in steps. First I show that all the policy functions are linear in $k$, which implies an aggregation result. Second I show that, given choice of $c$ and $k^{\prime}$, the choices of $d, s_{L}, s_{N L}$ and $i$ reduce to an arbitrage condition. Third I solve a relaxed problem, converting the entrepreneur's nonlinear budget set into a weakly larger linear one and show that there is a simple static characterization of the consumption-savings decision. Based on the solution to the relaxed problem it is possible to derive supply, demand and a market clearing condition. Finally I show that the equilibrium price must satisfy the market-clearing condition whether or not the solutions to the two programs coincide. 
Linearity of policy functions. The constraint set in program (9) is linear in $k$ and the utility function is homothetic. Hence the policy functions $c(k, A, X), k^{\prime}(k, A, X), i(k, A, X)$, $s_{L}(k, A, X), s_{N L}(k, A, X)$ and $d(k, A, X)$ are all linear in $k$. This implies the following result:

Lemma 1. Prices and aggregate quantities do not depend on the distribution of capital holdings, only on total capital $K$.

By Lemma $1,\{Z, K\}$ is a sufficient state variable; in order to compute aggregate quantities and prices it is not necessary to know the distribution $\Gamma$.

Buying, selling and investing decisions. Take the choice of $k^{\prime}$ as given. The entrepreneur's problem then reduces to choosing $d, s_{L}, s_{N L}$ and $i$ to maximize $c$. This program is linear so the entrepreneur will generically choose corner solutions. The decision to keep or sell lemons is trivial: as long as $p>0$ the entrepreneur will sell the lemons $\left(s_{L}=\lambda k\right)$, since they are worthless to him if kept. The decisions to keep or sell nonlemons and to invest in new projects or in purchasing projects depend on $A$. The return (i.e. the number of $t+1$ projects obtained per consumption good spent) from buying projects is $A^{M} \equiv \frac{\gamma\left(1-\lambda^{M}\right)}{p}$. I refer to this as the market rate of return. ${ }^{8}$ Conversely, the number of $t+1$ nonlemon projects an entrepreneur must give up to obtain one consumption good is $\frac{\gamma}{p}>A^{M}$. The return on investing is simply $A$. This implies that the optimal choices of $d, s_{N L}$ and $i$ are given by two cutoffs, shown in figure 2 .

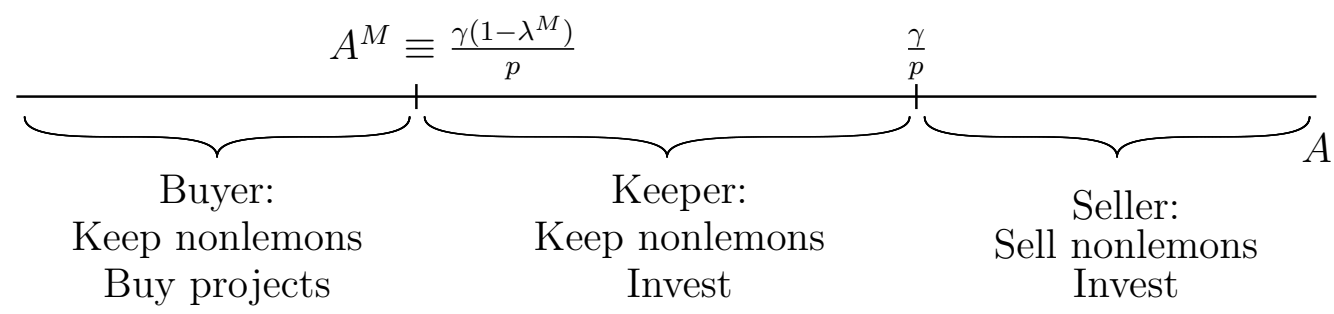

Figure 2: Buying, selling and investing decision as a function of $A$

For $A<A^{M}$, entrepreneurs are Buyers: the return from buying is greater than the return from investing so $i \geq 0$ and $s_{N L} \geq 0$ bind and $d>0$. For $A \in\left[A^{M}, \frac{\gamma}{p}\right]$ entrepreneurs are Keepers: investing offers a higher return than buying but not higher than the opportunity cost of selling nonlemons at the market price, so the entrepreneur neither buys projects nor sells nonlemons; $d \geq 0$ and $s_{N L} \geq 0$ bind and $i>0$. For $A>\frac{\gamma}{p}$ entrepreneurs are Sellers: the return from investing is high enough for the entrepreneurs to sell nonlemons in order to finance investment; $d \geq 0$ and $s_{N L} \leq(1-\lambda) k$ bind and $i>0 .{ }^{9}$ Combining these arbitrage conditions

\footnotetext{
${ }^{8}$ Noting, however, that it involves two different goods (projects and consumption goods) as well as two different dates.

${ }^{9}$ This assumes that $k^{\prime} \geq \gamma(1-\lambda) k$ so the entrepreneur wants more capital that just his own nonlemons. If instead $k^{\prime}<\gamma(1-\lambda) k$ (which by lemma 4 below is inconsistent with equilibrium), then Buyers and Keepers would choose $i=d=0$ and $s_{N L}>0$ while Sellers would choose $d=0, s_{N L}=(1-\lambda) k$ and $i>0$.
} 
with the constraint from program (9) yields the following lemma:

Lemma 2. Given $k^{\prime}$, the optimal $d, s_{L}, s_{N L}$ and $i$ are given by

\begin{tabular}{|l|l|l|l|}
\hline & Buyers: $A \in\left[0, A^{M}\right]$ & Keepers: $A \in\left(A^{M}, \frac{\gamma}{p}\right]$ & Sellers: $A \in\left(\frac{\gamma}{p}, \infty\right)$ \\
\hline$s_{L}=$ & $\lambda k$ & $\lambda k$ & $\lambda k$ \\
\hline$d=$ & $\max \left\{\frac{k^{\prime}-\gamma(1-\lambda) k}{\gamma\left(1-\lambda^{M}\right)}, 0\right\}$ & 0 & 0 \\
\hline$s_{N L}=$ & $\max \left\{\frac{\gamma(1-\lambda) k-k^{\prime}}{\gamma}, 0\right\}$ & $\max \left\{\frac{\gamma(1-\lambda) k-k^{\prime}}{\gamma}, 0\right\}$ & $(1-\lambda) k$ \\
\hline$i=$ & 0 & $\max \left\{\frac{k^{\prime}-\gamma(1-\lambda) k}{A}, 0\right\}$ & $\frac{k^{\prime}}{A}$ \\
\hline
\end{tabular}

Consumption-savings decision under a relaxed budget set. An entrepreneur with investment opportunity is $A$ must choose $\frac{c}{k}$ and $\frac{k^{\prime}}{k}$ from his budget set, shown in figure 3 .

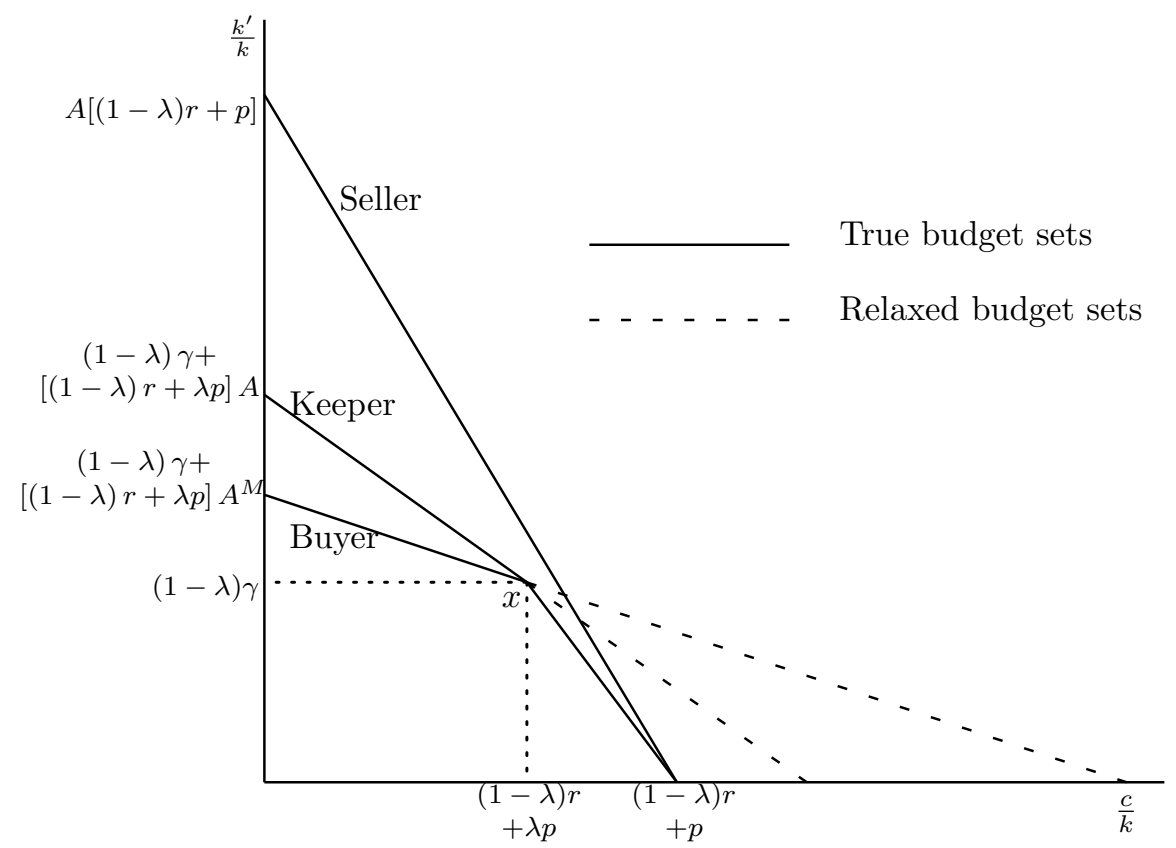

Figure 3: Budget sets

Point $x$ represents an entrepreneur who chooses $s_{L}=\lambda k$ and $i=s_{N L}=d=0$, an option available to all entrepreneurs. He simply consumes the dividends $(1-\lambda) r k$ and the proceeds from selling lemons $\lambda p k$, and enters period $t+1$ with $(1-\lambda) \gamma k$ projects. Consider first the decision of a Keeper. If he wishes to increase consumption beyond point $x$ he must sell nonlemons, which means giving up $\frac{\gamma}{p}$ future projects for each additional unit of consumption. If instead he wishes to carry more projects into $t+1$, he invests with rate of transformation $A$. Hence the budget constraint is kinked: to the right of $x$ the slope is $-\frac{\gamma}{p}$ whereas to the left it is $-A$. Consider next a Buyer. His budget set is the same as for the Keeper except that the return he obtains from saving beyond point $x$ is the market return $A^{M}$, which is higher than his individual return on investment $A$ but lower than that of Keepers. Lastly, a Seller will sell 
all his projects and his budget constraint is linear with constant slope $-A$.

Define the entrepreneur's virtual wealth as

$$
W(k, A, X) \equiv\left[\lambda p(X)+(1-\lambda)\left(r(X)+\max \left\{p(X), \frac{\gamma}{\max \left\{A, A^{M}(X)\right\}}\right\}\right)\right] k
$$

Virtual wealth corresponds to to the extension of the left half of the budget constraint onto the horizontal axis. It consists of the goods the entrepreneur has (dividends plus proceeds of selling lemons) plus the nonlemon projects, valued at the maximum of either their sale price $p$ or their replacement cost $\frac{\gamma}{\max \left\{A, A^{M}(X)\right\}}$. The linear budget set $\frac{k^{\prime}}{k} \leq \max \left\{A, A^{M}(X)\right\}\left[\frac{W(k, A, X)}{k}-\frac{c}{k}\right]$ is weakly larger than the true kinked budget, so substituting it in program (9) leads to the following relaxed program:

$$
\begin{aligned}
V(k, A, X) & =\max _{c, k^{\prime}}\left[u(c)+\beta \mathbb{E}\left[V\left(k^{\prime}, A^{\prime}, X^{\prime}\right) \mid X\right]\right] \\
\text { s.t. } \quad k^{\prime} & =\max \left\{A, A^{M}(X)\right\}[W(k, A, X)-c]
\end{aligned}
$$

Lemma 3. Under program (12), the entrepreneur's consumption is c $(k, A, X)=(1-\beta) W(k, A, X)$

Due to log preferences, entrepreneurs will always choose to consume a fraction $1-\beta$ of their virtual wealth and save the remaining $\beta$, by some combination of keeping their old nonlemons, buying projects and physical investment. Note that the entrepreneur's decision, while rational and forward looking, does not depend on the transition density $\Pi\left(X^{\prime} \mid X\right)$ or on the stochastic process for $A$. This feature will make it possible to solve for the equilibrium statically.

Notice that the function $W$ is decreasing in $A$. Different agents have different valuations of projects but asymmetric information prevents them from trading away those differences. In that sense, capital is illiquid. Furthermore, Lemma 3 implies that high- $A$ agents who value projects the least also consume less, so project valuation is negatively correlated with the marginal utility of consumption. Therefore agents would be willing to save in a risk-free asset with a lower expected return, a premium that would disappear if there was symmetric information. Kiyotaki and Moore (2008) find that a similar premium arises if resaleability constraints prevent entrepreneurs from reselling a fraction of their projects. Here instead the difference between the values placed on projects by entrepreneurs with different investment opportunities is derived endogenously as a result of asymmetric information.

Supply and demand under the relaxed program. By (10), the supply of projects will include all the lemons plus the nonlemons from Sellers. Hence

$$
S(p)=\left[\lambda+(1-\lambda)\left(1-F\left(\frac{\gamma}{p}\right)\right)\right] K
$$


This implies a market proportion of lemons of

$$
\lambda^{M}(p)=\frac{\lambda}{\lambda+(1-\lambda)\left(1-F\left(\frac{\gamma}{p}\right)\right)}
$$

and a market rate of return of: ${ }^{10}$

$$
A^{M}(p)=\frac{\gamma}{p}\left(1-\lambda^{M}(p)\right)=\frac{\gamma}{p} \frac{(1-\lambda)\left(1-F\left(\frac{\gamma}{p}\right)\right)}{\lambda+(1-\lambda)\left(1-F\left(\frac{\gamma}{p}\right)\right)}
$$

Demand for projects will come from Buyers. By Lemma 3, under the relaxed program they choose $k^{\prime}=\beta A^{M} W(k, A, X)$. By Lemma 2, they each demand $\frac{k^{\prime}-\gamma(1-\lambda) k}{\gamma\left(1-\lambda^{M}\right)}$ projects. Using (11) and adding over all Buyers, demand for projects will be:

$$
D(p)=\left(\beta\left[\lambda+(1-\lambda) \frac{r}{p}\right]-\frac{(1-\beta)(1-\lambda)}{1-\lambda^{M}(p)}\right) F\left(A^{M}(p)\right) K
$$

Market clearing requires

$$
S(p) \geq D(p) \text { with equality whenever } p>0
$$

Equilibrium conditions under the true program.

Lemma 4. $D>0$ only if the solutions to programs (9) and (12) coincide for all entrepreneurs

The solutions to programs (9) and (12) will not coincide whenever in the relaxed program, some entrepreneurs wish to choose points to the right of $x$. Lemma 4 states that if this is the case there will be no demand for projects. Therefore equilibrium prices can be found simply by solving (14)-(18). If a positive solution is found, then the relaxed program has yielded the correct solution; otherwise the equilibrium price is zero. Omitting the dependence on the state $X$, I simply denote the equilibrium price by $p^{*}$.

Once $p^{*}$ is determined, it is straightforward to solve, also statically, for the rest of the equilibrium objects. $\lambda^{M}$ and $A^{M}$ follow from (15) and (16). If $p^{*}>0$ then virtual wealth and, by Lemma 3 , consumption for each entrepreneur can be found using (11) and $s_{L}, s_{N L}, d$ and $i$ are given by (10). If instead the only solution to (18) is $p^{*}=0$, it is still possible to solve the relaxed problem (12), which results in

$$
k^{\prime}=\beta(1-\lambda)(A r+\gamma) k
$$

\footnotetext{
${ }^{10}$ Define $A^{M}(0) \equiv 0$
} 
This satisfies $k^{\prime} \geq \gamma(1-\lambda) k$ iff $A \geq \bar{A} \equiv \frac{\gamma}{r} \frac{(1-\beta)}{\beta}$. Hence for entrepreneurs with $A \geq \bar{A}$, consumption and investment can be computed in the same way as when $p>0$ whereas entrepreneurs with $A<\bar{A}$ chose $c=(1-\lambda) r k$ and $k^{\prime}=\gamma(1-\lambda) k$.

Aggregate capital accumulation is found by replacing the equilibrium values of $i$ into the law of motion of capital (2), yielding

$$
\begin{aligned}
\frac{K^{\prime}}{K} & =\gamma(1-\lambda)+\int_{A^{M}}^{\frac{\gamma}{p}}[\beta A[\lambda p+(1-\lambda) r]-(1-\beta)(1-\lambda) \gamma] d F(A) \\
& +\int_{\frac{\gamma}{p}}^{\infty} \beta A[p+(1-\lambda) r] d F(A)
\end{aligned}
$$

In general, the market return $A^{M}(p)$ can be either increasing or decreasing in $p$. An increase in the price has a direct effect of lowering returns by making projects more expensive and an indirect effect of improving returns by increasing the proportion of entrepreneurs who choose to sell their nonlemons. This implies that there could be more than one solution to (18). I assume that the equilibrium price is given by the highest solution. Furthermore, there could exist a price $p^{\prime}>p^{*}$ such that $A^{M}\left(p^{\prime}\right)>A^{M}\left(p^{*}\right)$ even when $p^{*}$ is the highest solution to (18). Stiglitz and Weiss (1981) argue that when this is the case the equilibrium concept used above is not reasonable and it would be more sensible to assume that Buyers set a price above $p^{*}$ that maximizes their return and ration the excess supply. For some of the results below, it will simplify the analysis to just assume that parameters are such that the issue does not arise: ${ }^{11}$

Assumption 1. $A^{M}(p)$ is decreasing

\subsection{Equivalence with an economy with taxes}

As shown in figure 2, asymmetric information introduces a wedge between the return obtained by Buyers, $A^{M}$, and the return given up by Sellers, $\frac{\gamma}{p}$. This wedge is isomorphic to the wedge that would be introduced by imposing a tax on the sales of projects.

Consider the economy with borrowing constraints and symmetric information of section 2.2 , but now assume that the government imposes an ad-valorem tax of $\tau(X)$ on purchases of projects. The total revenue $T(X)=\tau(X) p(X) S(p(X))$ collected from this tax is rebated to

\footnotetext{
${ }^{11}$ Assumption 1 holds if $h\left(\frac{\gamma}{p}\right) \leq \frac{p}{\gamma}\left[1+\frac{1-\lambda}{\lambda}\left(1-F\left(\frac{\gamma}{p}\right)\right)\right]$, where $h$ is the hazard function of $A$. If the hazard at $A=\frac{\gamma}{p}$ is too high, a small decrease in the price will lead a large fraction of the Sellers to become Keepers, increasing $\lambda^{M}$ and lowering market returns. Many common distributions fail to satisfy Assumption 1 at their right tail, i.e. for very low prices; for instance with $\lambda=0.1$, a standard lognormal fails Assumption 1 above its $91^{\text {st }}$ percentile. None of the results below require that Assumption 1 hold globally, and those that require that it hold locally are noted. When Assumption 1 fails, the main results still hold but need to be restated in terms of changes in the degree of rationing rather than changes in prices.
} 
entrepreneurs in proportion to their capital holdings. Entrepreneurs solve:

$$
\begin{gathered}
V(k, A, X)=\max _{c, k^{\prime}, i, s_{N L}, d}\left[u(c)+\beta \mathbb{E}\left[V\left(k^{\prime}, A^{\prime}, X^{\prime}\right) \mid X\right]\right] \\
\text { s.t. } \quad c+i+p(X)\left[d(1+\tau(X))-s_{N L}\right] \leq r(X)(1-\lambda) k+T(X) \frac{k}{K(X)} \\
k^{\prime}=\gamma\left[(1-\lambda) k+d-s_{N L}\right]+A i \\
i \geq 0, d \geq 0 \\
s_{N L} \in[0,(1-\lambda) k]
\end{gathered}
$$

This problem can be solved by the same steps used to solve program (9). Solving for the equilibrium conditions leads to the following equivalence result.

Proposition 2. Suppose $\tau(X)=\frac{\lambda^{M *}(X)}{1-\lambda^{M *}(X)}$, where $\lambda^{M *}(X)$ is the equilibrium value of the asymmetric information economy. Then prices and allocations of the symmetric-informationwith-taxes and the asymmetric information economies are identical.

In the asymmetric information economy, Buyers cannot avoid paying for useless lemons whenever they buy projects, which is like having to pay a tax on their purchases. Moreover, asymmetric information gives all entrepreneurs the possibility of earning $\lambda p k$ from selling lemons to others, which is the counterpart of the redistribution of the government's revenue. Overall, the effect of having a proportion $\lambda^{M}$ of lemons in the market is exactly equivalent to the one that would result from a tax at the rate $\tau=\frac{\lambda^{M}}{1-\lambda^{M}}$. The magnitude of this distortion is endogenous and, as discussed in section 4 below, it responds to aggregate shocks in specific ways.

The fact that the distortions are equivalent to taxes suggests that perhaps they could be undone by government policy. In principle, this is indeed possible. Suppose the government were to subsidize Buyers, paying for a fraction $\sigma(X)$ of the purchase price of any projects that they buy, and financed this subsidy with a tax on capital holdings. By the same reasoning that leads to Proposition 2, it can be shown that if $\sigma(X)=\lambda^{M}\left(p^{S I}(X)\right)$ (where $p^{S I}(X)$ is the price that would prevail under symmetric information and no taxes), then the allocation in the asymmetric information economy with subsidies would coincide with the one in the symmetric information economy and no taxes. The transaction subsidy would have to be greater in those states where the proportion of lemons is endogenously higher.

There are, however, both theoretical and practical objections to undertaking such a policy. First, since the policy involves a subsidy on transactions, the government would need a way to prevent the same people from trading the same project several times and collecting the subsidy each time. This would require, for instance, keeping track of who owned each project at the beginning of the period and only subsidizing purchases from the original owner. The government would also need to know entrepreneurs' capital holdings in order to impose the 
capital tax. But if it were possible for the government to know who owns what, some even simpler policies would also effective, such as mandating that every entrepreneur sell their entire portfolio every period, thus eliminating the adverse selection problem.

Second, even if it were feasible, the policy would not necessarily be desirable. Imagine implementing, for a single period, the tax-subsidy scheme that restores the symmetric information allocation. This policy always makes some entrepreneurs worse off. Consider an entrepreneur whose investment opportunity equals the symmetric-information threshold $A^{*}(X)$ so that with symmetric information he would choose to neither buy nor sell. With asymmetric information, he can still neither buy nor sell nonlemons but receives extra revenue from selling lemons so, abstracting from general-equilibrium effects on future factor prices, he is strictly better off. ${ }^{12}$ General equilibrium effects would make him even better off, since asymmetric information lowers capital accumulation (see Lemma 5 below), which raises the future marginal product of capital. Thus, a one-time intervention that restored the symmetric information allocation would not bring about a Pareto improvement, although perhaps it would if it were implemented every period and entrepreneurs were sufficiently patient.

\section{$4 \quad$ Aggregate shocks}

In order to analyze how the economy responds to shocks I first establish a preliminary result regarding how the isomorphic economy with symmetric information and taxes would respond to an exogenous increase in tax rates. This will be useful for determining what effects are due to the endogenous response of $\lambda^{M}$ to aggregate shocks.

Lemma 5. Suppose that in the economy with symmetric information and taxes there is an exogenous increase in the tax rate $\tau$. Then

\section{1. the price of projects decreases,}

2. the market returns for Buyers decrease and

\section{3. capital accumulation decreases if $\tau$ is close to zero.}

An increase in taxes increases the wedge between $A^{M}$ and $\frac{\gamma}{p}$. Parts 1 and 2 of Lemma 5 establish that this increase in the wedge manifests itself through both lower returns for Buyers and lower prices for Sellers. Both of these effects tend to lower capital accumulation. In addition, taxes have the effect of redistributing resources from Buyers and Sellers to all entrepreneurs,

\footnotetext{
${ }^{12}$ The fact that this policy does not bring about a Pareto improvement is just a manifestation of the fact that allocations in the static Akerlof model are interim constrained efficient, as proved by Myerson (1983) and Bigelow (1990).
} 
including Keepers. As with any tax, the relative incidence on Buyers and Sellers depends on elasticities. For small enough $\tau$, the elasticities of supply and demand are mechanically linked, as the density of marginal Buyers, $f\left(A^{M}\right)$, approaches that of marginal Sellers, $f\left(\frac{\gamma}{p}\right)$. Part 3 of Lemma 5 establishes that in this case the redistributive effect always goes against the higher- $A$ agents, reinforcing the effect of lower capital accumulation. ${ }^{13}$

\subsection{The response to aggregate shocks}

Thanks to assuming that entrepreneurs have log preferences, no labour income and a single asset to invest in, the equilibrium conditions are static. This implies that shocks will have the same effects no matter what is the stochastic process by which they are generated. Thus by answering the comparative statics question "how would the features of the model change if a parameter were different?" one also answers the impulse response question "how would the economy respond to a shock?"

Consider first the effects of productivity shocks, which can be of two kinds. Shocks to $Z$ affect the capacity of the economy to produce goods from the current capital stock while shocks to the distribution of $A$ affect the capacity of the economy to transform goods into capital. I refer to the first simply as a productivity shock and the second as an investment shock, and consider them in turn. Suppose first that there is a proportional productivity shock, lasting one period.

Proposition 3. If in equilibrium $p^{*}>0$ then a positive productivity shock leads to

1. a higher price for projects,

2. lower market returns for Buyers (if Assumption 1 holds),

3. a lower porportion of lemons in the market and

\section{4. higher capital accumulation (if Assumption 1 holds)}

Productivity shocks matter through their effect on the marginal product of capital $r=Y_{K}$. Higher $r$ means that entrepreneurs receive higher current dividends. Other things being equal, they want to save a fraction $\beta$ of the additional dividends. Sellers and Keepers do so through physical investment but Buyers attempt to buy more projects, bidding up the price (part 1) and lowering returns (part 2) to restore market-clearing. Higher prices then persuade marginal

\footnotetext{
${ }^{13}$ For $\tau$ away from zero, it is possible to construct counterexamples where $f\left(\frac{\gamma}{p}\right)$ is much higher than $f\left(A^{M}\right)$, so supply is much more elastic than demand. In this case it is possible for Sellers to be net beneficiaries of redistribution, so taxes can conceivably increase capital accumulation. However, the direct distortion increases more than proportionately with $\tau$ so in most examples increasing $\tau$ from a high starting point depresses capital accumulation even more than from a low starting point.
} 
Keepers to sell their nonlemons, reducing the severity of the lemons problem, as measured by the equivalent tax rate $\tau=\frac{\lambda^{M}}{1-\lambda^{M}}$. Note that productivity does not matter per se but rather for its effect on current dividends. A similar effect would result, for instance, if there was a helicopter drop of consumption goods on the economy.

This shows that, as in other macroeconomic models with financial constraints, balance sheet effects matter. However, unlike most of the transmission channels anaylzed in this literature, the effects do not work through the wealth of productive-but-constrained high- $A$ entrepreneurs; for given prices, the threshold $A$ for becoming a Seller rather than a Keeper is just $\frac{\gamma}{p}$ and does not respond to current dividends. Instead, what matters is the amount of consumption goods held by the low- $A$ entrepreneurs, because this determines the demand for assets and therefore asset prices and frictions. Focusing exclusively on how shocks affect the balance sheets of financially constrained agents would miss these potentially important general-equilibrium effects.

Turn now to an investment shock, represented as a proportional change in the investment opportunity of every entrepreneur, from $A$ to $\phi A$.

Proposition 4. A positive investment shock leads to

1. an ambiguous effect on the price of projects

2. higher market returns for Buyers (if Assumption 1 holds)

3. a lower proportion of lemons in the market and

\section{4. higher capital accumulation (if Assumption 1 holds)}

Proposition 4 implies that higher productivity in the project-producing sector also alleviates the lemons problem. Because physical investment has become more attractive, marginal Keepers decide to sell their nonlemons, improving the mix of projects. In this case, the effect on asset prices is ambiguous: the direct effect of the shock is to lower asset prices (because the shock lowers the production cost of new projects), but if the selection effect is strong enough, then prices could increase. Instead, the effect on returns for Buyers is unambiguously favourable, since the direct and selection effects go in the same direction.

In addition to productivity and investment shocks, it is also possible to analyze purely informational shocks. A negative information shock that increases informational asymmetry can be modeled as a one-period increase in $\lambda$, compensated by an increase in $K$ such that $(1-\lambda) K$ remains unchanged. This shock has no effect on the production possibility frontier of the economy and, with symmetric information, would have no effect on allocations.

Proposition 5. A negative information shock leads to

1. a lower price for projects, 


\section{2. lower market returns for Buyers,}

\section{3. a higher porportion of lemons in the market and}

\section{4. lower capital accumulation for $\lambda$ small enough.}

The increase in $\lambda^{M *}$ that results from this type of shock is equivalent to an exogenous increase in taxes, so Lemma 5 can be applied directly. One interpretation of this type shock may be the following. Suppose every period entrepreneurs receive an endowment of $\Delta K$ useless lemons, so the total number of lemons is $(\lambda+\Delta) K$ rather than $\lambda K$. However, in ordinary times it is possible to tell apart the endowment-lemons from the nonlemons, so their existence is irrelevant. A shock to $\lambda$ of the kind described above is equivalent to entrepreneurs losing the ability to detect endowment-lemons, a form of deterioration of information.

Business cycles may be generated by any combination of productivity, investment and perhaps information shocks. Propositions 3-5 jointly show that no matter what is the relative importance of either type of shock, financial market distortions (as measured by the implict tax) will be countercyclical or, to put it differently, liquidity will be procyclical.

For negative shocks, the adverse selection effect can be sufficiently strong that the price falls to zero and no nonlemons are traded, an outcome that I label a "market shutdown". ${ }^{14}$

Proposition 6. A sufficiently negative productivity, investment or information shock leads to a market shutdown.

When productivity is low, dividends are low so entrepreneurs have few consumption goods. For project demand to be positive, the market return must be high enough to persuade Buyers to give up their scarce consumption goods in return for additional projects (i.e. to choose $k^{\prime}$ above the kink in figure 3). In a world with symmetric information, the price would drop until the return from buying projects was sufficiently attractive to clear the market. With asymmetric information, the adverse selection effect places an upper bound on the $A^{M}(p)$ return function. If dividends are sufficiently low, the return required for demand to be positive exceeds this upper bound and there is no demand at any positive price. Similarly, when investment-productivity is low, the measure of entrepreneurs who are willing to sell nonlemons is low, which raises the fraction of lemons in the market and lowers returns. For large negative shocks, it does so to the point where demand is zero at any positive price.

The prediction of a market shutdown requires that the return function $A^{M}(p)$ have an upper bound. This feature is sensitive to the assumptions regarding the distribution of project qualities. For instance, suppose that instead of being worthless, lemons had low but positive

\footnotetext{
${ }^{14}$ At $p=0$, demand is indeterminate, so a market shutdown could equally mean no trade at all or just trade of lemons at a zero price.
} 
value. Then $A^{M}(p)$ would be unbounded because for sufficently low prices returns from buying would be arbitrarily large even if only lemons were being sold. Therefore lemons would always be traded at positive prices in equilibrium and there would be no market shutdowns. More generally, with many possible qualities, a necessary condition for $A^{M}(p)$ to be bounded is that the lower bound of the support of the distribution of project quality be zero. ${ }^{15}$

\subsection{The role of endogenous changes in distortions}

A way to isolate the role that asymmetric information plays in the transmission of aggregate shocks is to analyze how the response to shocks of this economy differs from that of an otherwise identical economy with symmetric information. In order to establish the right benchmark for comparison, I use the result from Proposition 2 and assume that in the symmetric information economy there are (fixed) taxes on transactions at a rate such that, absent the shock, prices and allocations in both economies would be exactly the same.

Proposition 7 . In response to a positive productivity shock

1. the price of projects increases more,

2. the market returns for Buyers fall less and

3. capital accumulation increases more (for $\lambda$ small enough) while in response to a positive investment shock

4. the price of projects falls less,

5. the market returns for Buyers increase more and

6. capital accumulation increases more (for $\lambda$ small enough)

in the asymmetric information economy than in the benchmark symmetric information economy.

One of the longstanding questions in macroeconomics is why the economy exhibits large fluctuations, given that it is hard to locate large exogenous shocks driving them. Proposition 7 shows that asymmetric information about asset qualities may be part of the answer, since it amplifies the effects of either type of shock on the real economy. Hence it can be one of the sources of the so-called financial accelerator. The role of asset markets in generating amplification has been noted before, for instance by Kiyotaki and Moore (1997). What is newer to this model is that, rather than being a fixed parameter as in Kiyotaki and Moore

\footnotetext{
${ }^{15}$ The same is true in Akerlof's model, as shown by Wilson (1980).
} 
(2005, 2008), the illiquidity of assets itself responds to shocks, which is a related but slightly different channel.

In addition to generating this amplification mechanism, the model can account for several stylized facts about the cyclical behaviour of real and financial variables. Eisfeldt and Rampini (2006) measure the volume of reallocation of used capital as well as various measures of the dispersion of the marginal product of capital across firms. They find that although the dispersion in marginal products seems countercyclical, the amount of reallocation is strongly procyclical, suggesting that there are strongly countercyclical frictions in the reallocation process. ${ }^{16}$ This is exactly the pattern predicted by increased adverse selection frictions in the model. As $\lambda^{M}$ increases, the gap between the investment-productivity of Sellers and Buyers increases, yet the volume of transactions falls.

Covas and Den Haan $(2011,2007)$ report that both debt and equity financing of US and Canadian firms are highly procyclical (except for equity for the very largest US firms), while retained earnings are only mildly procyclical. This is the pattern predicted by the model: in recessions, as the volume of financial transactions falls, firms will rely more on retained earnings to finance investment, whereas they will obtain more external financing (in the model, by selling assets) in expansions. This is in contrast to some other models of financial frictions. For instance, the key to the financial accelerator mechanism in Bernanke and Gertler (1989) is that in good times firms have abundant retained earnings and therefore need to rely less on costly outside financing. Many other models, such as Kiyotaki and Moore (1997), assume that outside financing is a fixed fraction of firm's funding. Moreover, because it allows for market shutdowns after large negative shocks, the model can also account for sharp drops in the volume of financial transactions, such as have been reported by Ivashina and Scharfstein (2010) in the syndicated loan market, Adrian and Shin (2009) in the asset-backed securities market and Gorton and Metrick (2009) in the repo market in 2007-2009.

Choe et al. (1993) document that the number of firms issuing seasoned equity is procyclical and the negative price reaction on announcing these equity issues is countercyclical. This is also the pattern predicted by the model. Equations (14) and (15) imply that in the model the total volume of projects sold is $\frac{\lambda}{\lambda^{M}} K$, so increases in $\lambda^{M}$ translate directly into falls in the volume of sold projects. Furthermore, the price Buyers would be willing to pay for a project if it were randomly rather than adversely selected is $\frac{\gamma(1-\lambda)}{A^{M}}$, whereas the actual price, which takes into account that sold projects are adversely selected is $\frac{\gamma\left(1-\lambda^{M}\right)}{A^{M}}$. Hence the price of a project upon the announcement that it will be sold falls to a fraction $\frac{1-\lambda^{M}}{1-\lambda}<1$ of its pre-announcement

\footnotetext{
${ }^{16}$ Maksimovic and Phillips (2001) also report procyclical levels of asset reallocation. Gavazza (2011) studies the frictions in the market for used airplanes but does not focus on the question of cyclicality.
} 
price. ${ }^{17}$ This fall is greater in recessions, when $\lambda^{M}$ is higher. ${ }^{18}$

Justiniano, Primiceri and Tambalotti (2008) find, in an estimated quantitative model, that shocks to the efficiency of investment are the most important single driver of US business cycle fluctuations. Although they don't explicitly model financial transactions, they show that their measure of investment shocks is correlated with measures of the functioning of financial markets. Cyclical frictions of the kind generated by the model can account for this pattern. With higher frictions, marginal Buyers become Keepers (and therefore invest) and marginal Sellers become Keepers (and therefore invest less), lowering the average rate of transformation of consumption goods into capital. If capital formation is measured correctly, this effect will be captured as lower investment productivity. If instead capital formation is measured by simply adding up investment, frictions that lower the rate of transformation of consumption goods into capital will result in an overestimate of the capital stock, which will be captured as lower TFP in future periods. ${ }^{19}$ This may help explain the long periods of low (measured) productivity growth that follow some financial crises, as documented for instance by Hayashi and Prescott (2002) for Japan in the 1990s.

\section{Final remarks}

This paper explores the macroeconomic implications of asymmetric information about asset quality when trading assets is the only way to undertake intertemporal transactions. Informational asymmetry acts like a tax on transactions which distorts the flow of investment. The distortion is sensitive to macroeconomic shocks and, for all the types of shocks considered, becomes more severe when the economy suffers negative shocks. This provides an explanation for financial markets' observed fragility with respect to bad shocks, provides a channel for the amplification of aggregate shock and generates cyclical frictions that can account for observed patters of firms' investment, financing and reallocation decisions.

One limitation of the model is that entrepreneurs are only allowed to accumulate capital and not other assets not subject to asymmetric information such as money or government bonds. Preliminary explorations of multiple-asset extensions of the model suggest that trade in these liquid assets can enable intertemporal trades but at the same time worsen the adverse selection in other asset markets, with ambiguous effects on allocations.

A related limitation is that the model does not distinguish between various types of financial

\footnotetext{
${ }^{17}$ Technically, in the model there is no price for projects that are not sold. The fall is with respect to the price at which the project would trade among uninformed Buyers.

${ }^{18}$ Jovanovic and Braguinsky (2004) study announcement effects in a model of mergers with asymmetric information, but do not focus on cyclical effects.

${ }^{19}$ Buera and Moll (2011) analyze how different financial market frictions would be detected in the accounting methodology of Chari et al. (2007).
} 
transactions such as asset sales, issues of securities, etc. Hence it only has predictions for the cyclical pattern of these transactions as a whole. A natural next step would be to ask whether macroeconomic shocks have differential effects on different segments of financial markets, in a model where different transactions each play a role.

Another possible extension of the model, undertaken in the working paper version, is to endogenize the degree of information asymmetry as a result of experience gained in the course of trading. This can lead to dynamic feedback effects and create persistent effects from temporary shocks.

\section{A Proofs}

Proof of Lemma 1. $r(X)$ does not depend on the distribution of $k$ because $Y$ does not. For any given $p$ and $\lambda^{M}$, linearity of the policy functions and the fact that $A^{j}$ is independent of $k^{j}$ imply that $S_{L} S_{N L}$ and $D$ do not depend on the distribution of $k$ and therefore neither do the market clearing values of $p(X)$ and $\lambda^{M}(X)$. By linearity, neither do aggregate quantities.

Proof of Lemma 3. The Euler equation is:

$$
u_{c}=\beta \max \left\{A, A^{M}(X)\right\} \mathbb{E}\left[W_{k^{\prime}}\left(k^{\prime}, A^{\prime}, X^{\prime}\right) \mid X\right] u_{c^{\prime}}
$$

Given that $u^{\prime}(c)=\frac{1}{c}$, using (13) confirms that $c=(1-\beta) W(k, A, X)$ solves $(21)$. Proof of Lemma 4 .

Assume there is an entrepreneur for whom the solutions differ. For Sellers both programs are identical so it must be that at least one Buyer or Keeper chooses $k^{\prime}<(1-\lambda) \gamma k$. Then by revealed preference all Buyers choose $k^{\prime}<(1-\lambda) \gamma k$. Replacing in (10) yields $D=0$.

Proof of Proposition 2. Take any state $X$ and denote the equilibrium values under asymmetric information by $p^{*}$ and $\lambda^{M *}$. Conjecture that $p^{*}$ is the equilibrium price in the economy with taxes. The supply of projects is $S=(1-\lambda)\left(1-F\left(\frac{\gamma}{p^{*}}\right)\right)$ and tax revenue is

$$
\begin{aligned}
T & =\tau p^{*}(1-\lambda)\left(1-F\left(\frac{\gamma}{p^{*}}\right)\right) K \\
& =\frac{\lambda^{M *}}{1-\lambda^{M *}} p^{*}(1-\lambda)\left(1-F\left(\frac{\gamma}{p^{*}}\right)\right) K \\
& =\lambda p^{*} K
\end{aligned}
$$

Therfore the constraints on programs (9) and (20) are exactly equivalent. This means the solutions must be the same, which confirms that $p^{*}$ is an equilibrium price in the economy with 
taxes.

Proof of Lemma 5. Demand, supply, prices and government revenue can be expressed as:

$$
\begin{aligned}
D & =\left[\frac{\beta}{\gamma} A^{M}(p)\left[\tau(1-\lambda) p\left(1-F\left(\frac{\gamma}{p}\right)\right)+(1-\lambda) r\right]-(1-\beta)(1-\lambda)\right] F\left(A^{M}(p)\right) \\
S & =(1-\lambda)\left[1-F\left(\frac{\gamma}{p}\right)\right] \\
A^{M}(p, \tau) & =\frac{\gamma}{p(1+\tau)} \\
p\left(A^{M}, \tau\right) & =\frac{\gamma}{A^{M}(1+\tau)} \\
T & =\tau(1-\lambda) p\left(1-F\left(\frac{\gamma}{p}\right)\right)
\end{aligned}
$$

1. Market clearing implies

$$
\frac{d p}{d \tau}=\frac{\frac{\partial S}{\partial \tau}-\frac{\partial D}{\partial \tau}}{\frac{\partial D}{\partial p}-\frac{\partial S}{\partial p}}
$$

Taking derivatives and substituting:

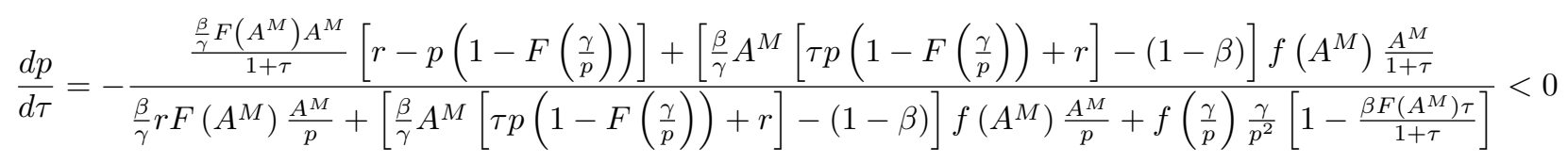

2. Market clearing implies

$$
\frac{d A^{M}}{d \tau}=\frac{\frac{\partial S}{\partial \tau}-\frac{\partial D}{\partial \tau}}{\frac{\partial D}{\partial A^{M}}-\frac{\partial S}{\partial A^{M}}}
$$

Taking derivatives and substituting:

$$
\frac{d A^{M}}{d \tau}=-\frac{f\left(A^{M}(1+\tau)\right) A^{M}\left[1-\frac{\tau}{1+\tau} \beta F\left(A^{M}\right)\right]+\frac{\beta F\left(A^{M}\right)}{(1+\tau)^{2}}\left(1-F\left(A^{M}(1+\tau)\right)\right)}{\frac{\beta}{\gamma} F\left(A^{M}\right) r+\left[\frac{\beta}{\gamma} A^{M}\left[\tau p\left(1-F\left(\frac{\gamma}{p}\right)\right)+r\right]-(1-\beta)\right] f\left(A^{M}\right)+f\left(A^{M}(1+\tau)\right)\left[1+\tau-\tau \beta F\left(A^{M}\right)\right]}<0
$$

3. Integrating $k^{\prime}$ over all entrepreneurs, $K^{\prime}$ is given by

$$
\begin{aligned}
K^{\prime} & =\int_{0}^{A^{M}}\left[\beta A^{M}(T+(1-\lambda) r)+\beta(1-\lambda) \gamma\right] d F(A) \\
& +\int_{A^{M}}^{\frac{\gamma}{p}}[\beta A(T+(1-\lambda) r)+\beta(1-\lambda) \gamma] d F(A) \\
& +\int_{\frac{\gamma}{p}}^{\infty}[\beta A(T+(1-\lambda) r)+\beta A(1-\lambda) p] d F(A)
\end{aligned}
$$

Taking derivatives:

$$
\frac{d K^{\prime}}{d \tau}=(1-\lambda) \beta\left[\begin{array}{c}
p\left(1-F\left(\frac{\gamma}{p}\right)\right)\left[A^{M} F\left(A^{M}\right)+\int_{A^{M}}^{\infty} A d F(A)\right]+\left(\tau p\left(1-F\left(\frac{\gamma}{p}\right)\right)+r\right) \frac{d A^{M}}{d \tau} \\
+\left[\int_{\frac{\gamma}{p}}^{\infty} A d F(A)+\tau\left[1-F\left(\frac{\gamma}{p}\right)+p f\left(\frac{\gamma}{p}\right) \frac{\gamma}{p^{2}}\right]\left[A^{M} F\left(A^{M}\right)+\int_{A^{M}}^{\infty} A d F(A)\right]\right] \frac{d p}{d \tau}
\end{array}\right]
$$


Replacing with the expressions from parts 1 and 2 and using the fact that as $\tau \rightarrow 0$, $F\left(A^{M}\right) \rightarrow F\left(\frac{\gamma}{p}\right)$ and $f\left(A^{M}\right) \rightarrow f\left(\frac{\gamma}{p}\right)$, this expression reduces to

$$
\begin{aligned}
\frac{x}{(1-\lambda) \beta} \frac{d K^{\prime}}{d \tau}= & -\left[\left(\frac{r}{p}-\beta\left[\frac{r}{p}+1\right]\left(1-F\left(A^{M}\right)\right) F\left(A^{M}\right)\right) p A^{M}\right] f\left(A^{M}\right) \\
& -\left[\frac{\beta}{\gamma} F\left(A^{M}\right) p r\left[A^{M}\left(1-F\left(A^{M}\right)\right)^{2}+F\left(A^{M}\right)\left(\frac{p}{r}+1\right)(1-\beta) \int_{A^{M}}^{\infty} A d F(A)\right]\right]<0
\end{aligned}
$$

where

$$
x \equiv \frac{\beta}{\gamma} F\left(A^{M}\right) r+\left[\frac{\beta}{\gamma} A^{M}\left[\tau p\left(1-F\left(\frac{\gamma}{p}\right)\right)+r\right]-(1-\beta)\right] f\left(A^{M}\right)+f\left(\frac{\gamma}{p}\right)(1+\tau)\left[1-\beta F\left(A^{M}\right) \frac{\tau}{1+\tau}\right]>0
$$

Proof of Proposition 3. The only effect of higher productivity on equilibrium conditions is through an increase in $r$.

1. Fixing $p$, higher $r$ increases demand but has no effect on supply. If $\frac{\partial[D(p)-S(p)]}{\partial p}<0$ (which must hold at that highest solution (18)), the equilibrium price must rise to restore market clearing.

2. The result follows from part 1 and Assumption 1.

3. The result follows from part 1 and (15).

4. By part 1, the terms inside the integrals of equation 19 are increasing in $r$. By part 3, $A^{M}$ is decreasing in $r$. Since both terms inside the integrals are positive but the second is greater than the first, the results follows.

Proof of Proposition 4. Denote the original equilibrium by $\left\{p^{*}, \lambda^{M *}, A^{M *}\right\}$ and decompose the effect of an increase in $\phi$ into two steps: (i) the effect of increasing $\phi$ while decreasing $r$ to leave $\phi r$ constant and (ii) the effect of restoring $r$ to its original value. For step (i), equations (14)(17) imply that $\left\{p, \lambda^{M}, A^{M}\right\}=\left\{\frac{p^{*}}{\phi}, \lambda^{M *}, \phi A^{M *}\right\}$ is an equilibrium for any $\phi$. Furthermore, equation (11) implies that each entrepreneur's proportional increase in $\max \left\{A^{M}, A\right\}$ is exactly offset by a proportional decrease in virtual wealth and $\frac{K^{\prime}}{K}$ does not change with $\phi$. Step (ii) consists of increasing $r$, so parts 3 and 4 follow from Proposition 3. The overall effect on prices (part 1) is ambiguous because step (i) lowers prices and step (ii) raises them. To establish part 2 , notice that in the symmetric information economy with taxes, (22) implies that for fixed taxes, $D-S$ is decreasing in $\phi$, so an increase in $\phi$ means a lower price and higher $A^{M}$. By part 3 , implicit taxes are lower when $\phi$ increases and by Lemma 5 this further increases $A^{M}$. 
Proof of Proposition 6. First note that $A^{M}(p)$ is bounded because (i) it is continuous in $p$, (ii) $\lim _{p \rightarrow \infty} A^{M}(p)=0$ and (iii) using l'Hôpital's Rule

$$
\lim _{p \rightarrow 0} A^{M}(p)=\lim _{p \rightarrow 0} \frac{f\left(\frac{\gamma}{p}\right)}{p^{2}} \frac{\gamma^{2}(1-\lambda)}{\lambda}
$$

which must be equal to zero for $A$ to have a finite mean.

Using(17), whenever

$$
\max _{p} A^{M}(p)<\frac{\gamma}{r} \frac{(1-\beta)}{\beta}
$$

then $D(p)<\beta \lambda F\left(A^{M}(p)\right)$, which is less than the supply of lemons from Buyers alone, which implies $p^{*}=0$.

Since $A^{M}(p)$ is bounded, condition (23) is met for sufficiently low $r$ or, using (16), for sufficiently high $\lambda$, which proves the result for productivity and information shocks. Also because $A^{M}(p)$ is bounded, then

$$
A^{M}(p, \phi)=\frac{\gamma}{p} \frac{(1-\lambda)\left(1-F\left(\frac{\gamma}{p \phi}\right)\right)}{\lambda+(1-\lambda)\left(1-F\left(\frac{\gamma}{p \phi}\right)\right)}
$$

converges uniformly to zero as $\phi \rightarrow 0$, so a sufficiently large investment shock also ensures that condition (23) is met.

Proof of Proposition 5. For given prices, equation (15) implies that $\lambda^{M *}$ is increasing in $\lambda$. In addition, $D(p)-S(p)$ is decreasing in $\lambda$, so $p$ must fall to restore market clearing. By (15), this reinforces the increase in $\lambda^{M *}$.

Proof of Proposition 7. The effect of the shock on each of the endogenous variables in the asymmetric information economy can be decomposed into the effect it has in the fixed- $\tau$ symmetric information economy plus the effect of the change in the implicit $\tau$. By part 3 of Proposition 3 and part 3 of Proposition 4 the implicit $\tau$ is decreasing for either positive shock. The comparisons then follow from Lemma 5.

\section{References}

Adrian, T. and Shin, H. S.: 2009, Money, liquidity, and monetary policy, American Economic Review 99(2), 600-605.

Akerlof, G. A.: 1970, The market for "lemons": Quality uncertainty and the market mechanism, The Quarterly Journal of Economics 84(3), 488-500. 
Bernanke, B. and Gertler, M.: 1989, Agency costs, net worth, and business fluctuations, American Economic Review 79(1), 14-31.

Bigelow, J. P.: 1990, Efficiency and adverse selection, Journal of Economic Theory 52(2), 380 -405 .

Bigio, S.: 2011, Endogenous liquidity and the business cycle, Technical report. New York University Working Paper.

Bolton, P., Santos, T. and Scheinkman, J. A.: 2009, Outside and inside liquidity, NBER Working Papers 14867, National Bureau of Economic Research, Inc.

Buera, F. J. and Moll, B.: 2011, Aggregate implications of a credit crunch, Technical report. Princeton University Working Paper.

Carlstrom, C. T. and Fuerst, T. S.: 1997, Agency costs, net worth, and business fluctuations: A computable general equilibrium analysis, The American Economic Review 87(5), 893-910.

Chari, V. V., Kehoe, P. J. and McGrattan, E. R.: 2007, Business cycle accounting, Econometrica $\mathbf{7 5}(3), 781-836$.

Choe, H., Masulis, R. W. and Nanda, V. K.: 1993, Common Stock Offerings Across the Business Cycle: Theory and Evidence, Journal of Empirical Finance 1(1), 3-31.

Covas, F. and Den Haan, W. J.: 2007, Cyclical behavior of debt and equity using a panel of canadian firms, (07-44).

Covas, F. and Den Haan, W. J.: 2011, The cyclical behavior of debt and equity finance, The American Economic Review 101, 877-899.

Daley, B. and Green, B.: 2009, Waiting for news in the dynamic market for lemons. mimeo, Stanford University.

de Meza, D. and Webb, D. C.: 1987, Too much investment: A problem of asymmetric information, The Quarterly Journal of Economics 102(2), 281-92.

DeMarzo, P. and Duffie, D.: 1999, A liquidity-based model of security design, Econometrica 67(1), 65-100.

Eisfeldt, A. L.: 2004, Endogenous liquidity in asset markets, Journal of Finance 59(1), 1-30.

Eisfeldt, A. L. and Rampini, A. A.: 2006, Capital reallocation and liquidity, Journal of Monetary Economics 53(3), 369-399. 
Gavazza, A.: 2011, The role of trading frictions in real asset markets, American Economic Review 101(4), 1106-43.

Gorton, G. B. and Metrick, A.: 2009, Securitized banking and the run on repo, NBER Working Papers 15223, National Bureau of Economic Research, Inc.

Hart, O. and Moore, J.: 1994, A theory of debt based on the inalienability of human capital, The Quarterly Journal of Economics 109(4), 841-879.

Hayashi, F. and Prescott, E. C.: 2002, The 1990s in japan: A lost decade, Review of Economic Dynamics 5(1), 206 - 235.

Hendel, I. and Lizzeri, A.: 1999, Adverse selection in durable goods markets, The American Economic Review 89(5), 1097-1115.

Hendel, I., Lizzeri, A. and Siniscalchi, M.: 2005, Efficient sorting in a dynamic adverse-selection model, The Review of Economic Studies 72(2), 467-497.

Holmström, B. and Tirole, J.: 1998, Private and public supply of liquidity, Journal of Political Economy 106(1), 1-40.

House, C. L.: 2006, Adverse selection and the financial accelerator, Journal of Monetary Economics 53(6), 1117-1134.

Ivashina, V. and Scharfstein, D.: 2010, Bank lending during the financial crisis of 2008, Journal of Financial Economics 97(3), 319 - 338.

Jovanovic, B. and Braguinsky, S.: 2004, Bidder discounts and target premia in takeovers., American Economic Review 94(1), 46 - 56.

Justiniano, A., Primiceri, G. E. and Tambalotti, A.: 2008, Investment shocks and the relative price of investment. Working Paper, Northwestern University.

Kiyotaki, N. and Moore, J.: 1997, Credit cycles, Journal of Political Economy 105(2), 211-48.

Kiyotaki, N. and Moore, J.: 2003, Inside money and liquidity, ESE Discussion Papers 115, Edinburgh School of Economics, University of Edinburgh.

Kiyotaki, N. and Moore, J.: 2005, 2002 lawrence r. klein lecture liquidity and asset prices, International Economic Review 46(2), 317-349.

Kiyotaki, N. and Moore, J.: 2008, Liquidity, business cycles and monetary policy. mimeo, Princeton University. 
Maksimovic, V. and Phillips, G.: 2001, The market for corporate assets: Who engages in mergers and asset sales and are there efficiency gains?, The Journal of Finance 56(6), 20192065.

Malherbe, F.: 2009, Self-fulfilling liquidity dry-ups. mimeo, ECARES.

Mankiw, N. G.: 1986, The allocation of credit and financial collapse, The Quarterly Journal of Economics 101(3), 455-70.

Myers, S. C. and Majluf, N. S.: 1984, Corporate financing and investment decisions when firms have information that investors do not have, Journal of Financial Economics 13(2), 187 221.

Myerson, R. B.: 1983, Analysis of two bargaining problems with incomplete information, Discussion Papers 582, Northwestern University, Center for Mathematical Studies in Economics and Management Science.

Nachman, D. and Noe, T.: 1994, Optimal design of securities under asymmetric information, Review of Financial Studies 7(1), 1-44.

Stiglitz, J. E. and Weiss, A.: 1981, Credit rationing in markets with imperfect information, American Economic Review 71(3), 393-410.

Wilson, C.: 1980, The nature of equilibrium in markets with adverse selection, The Bell Journal of Economics 11(1), 108-130. 